\title{
Clinical Competence and Associated Factors Among Nurses working in Selected Health Institutions of Ilu AbaBor Zone, South-West Ethiopia: A Cross Sectional Study
}

\author{
Bonsa Amsalu Geleta ", Sanbato Tamiru Dingata, Milkias Dugassa Emanu \\ Department of Nursing, College of Health Sciences, Mettu University, Mettu, Ethiopia \\ Email address: \\ bonsaamsalu380@gmail.com (B. A. Geleta), bonsa.amsalu@meu.edu.et (B. A. Geleta) \\ ${ }^{*}$ Corresponding author
}

\section{To cite this article:}

Bonsa Amsalu Geleta, Sanbato Tamiru Dingata, Milkias Dugassa Emanu. Clinical Competence and Associated Factors Among Nurses working in Selected Health Institutions of Ilu AbaBor Zone, South-West Ethiopia: A Cross Sectional Study. International Journal of Biomedical Engineering and Clinical Science. Vol. 7, No. 2, 2021, pp. 14-21. doi: 10.11648/j.ijbecs.20210702.11

Received: November 22, 2020; Accepted: December 7, 2020; Published: April 20, 2021

\begin{abstract}
Introduction: Clinical competence is fundamental element in the provision of nursing care and now a day it is the concern and the centre of attention for managers and the healthcare systems. Higher level of clinical competence has a positive impact on patient's health outcome and nurse's job performance and satisfaction. However, there is limited information on clinical competence of nurse in Ethiopia. Objective: The objective of this study was to assess clinical competency and associated factors among nurses working in selected health institutions of Illubabor zone, oromia regional state, north-west Ethiopia, 2019. Methods: Institution based cross-sectional study was employed on 160 nurses in two hospitals and 20 health centres. Simple random sampling technique was employed to select study participants. Structured self-administered questionnaire was used to collect data. Independent t-test and analysis of variance (ANOVA) were used to identify factors associated with clinical competence. The statistical significance was set at $\mathrm{p}<0.05$. Results: Out 160 recruited, 156 participants were responded the questionnaire, making the response rate of $97.5 \%$. The overall clinical competence of participants was 2.23 $(\mathrm{SD}=0.6)$ which indicates moderate level of clinical competence. Participants had higher competence score on Legal/ethical dimension and lower competence score on teaching coaching dimension. Age, marital status, level of education, work experience, type of health facility, average income, and current position, retrieval of newly published information, previous training, and frequency of trainings, having guideline/manual and using guideline/manual currently were the identified factors association with clinical competence of nurses. Conclusion: In the current rapidly changing healthcare environment, the need for clinical competence among nurses is continually increasing. However, clinical competence of nurses in the current study was inadequate in which the overall score of participants was almost only half of total score. It is recommended that health policy makers should set strategies to assess the clinical competence of nurses on a periodic basis in order to assure quality nursing service.
\end{abstract}

Keywords: Clinical Competence, Competence, Nurse, Associated Factors

\section{Introduction}

Clinical competence is a combination of skills, knowledge, attitudes, values and abilities that bring about effective or high performance in professional positions [1]. Clinically competent nurse is ability to perform nursing activities safely according to predetermined standards within the scope of practice, in coordination with other members of the health care providers [2]. It consists of seven dimensions including helping role, teaching-coaching, diagnostic functions, managing situations, therapeutic interventions, ensuring quality and work role [3]. 
Clinical competence is basic element in the provision of nursing care and now a day's clinical competence of nurses in the health institution is the concern and the centre of attention for managers and the healthcare systems [4]. This is due to the fact that the health care system needs competent nurse professionals to ensure quality of nursing care and nurses' professional competency is a key factor to improve quality of nursing care given to patients [5]. Nurses are also one of the key components of the health care system and play an important role in providing highquality health services [6]. Generally, clinical competence of nurse is the main aim of the nursing profession because the quality of health care is primarily depends on the clinical competence of nurses [7].

The competence of nurse professionals has a significant impact on quality of care and is closely associated with job performance, satisfaction and absenteeism and patient safety [8]. It is approved that a higher level of clinical competence has a positive impact on patient's health outcome and nurse's job satisfaction [3, 10]. Several studies have inconsistent findings on clinical competence of nurses working in different health institutions in which clinical competence of $n$ nurses were reported as high [11], moderate [12] and moderate to low [13]. In conclusion there is shortage of competent globally [14]. As the result of this, health care administrator faces challenges to get competent and experienced nurses [15]. Previous studies revealed that several factors have been affecting clinical competence of nurses. Study done in Finland showed that nurse education, experience, professional development, independence, and work satisfaction as well as the evaluation of quality of nursing care were identified as factors associated with nurse competence [16].

To sum up evidence indicated that a high level of clinical competence in nurses has a significant positive effect on their performance in health institution. Therefore, continuous assessment of clinical competence is crucial and should be taken into consideration at all health care setting. However, studies on clinical competence and its associated factors are scares in Ethiopia. Hence, the present study was aimed to assess clinical competence of nurses working in selected health institutions of Ilu AbaBor zone, South West Ethiopia. The result of this study will therefore guide nurses, nurse educators and others concerned body in taking appropriate measures that will contribute in better provision of quality nursing care. It is also hoped that the finding from this study may be helpful in designing a future nursing educational plan and in-service training program for professional nurses in Ethiopia.

\section{Methods}

\subsection{Study Area and Period}

The study was conducted in selected health institutions of Illubabor Zone. Ilu AbaBor zone is one of the Oromia regional state situated at South West of the region and Mettu townis serving as the capital city of the zone and it is located $600 \mathrm{KM}$ away from Addis Ababa the capacity of Ethiopia. Totally the zone has one referral hospital, one general hospital and 39 health centers. The study period was spanned from 1 to 30 January, 2019.

\subsection{Study Design}

Institution based cross-sectional study was employed.

\subsection{Source Population}

All nurses who working in selected health institutions of Ilu AbaBora zone.

\subsection{Study Populations}

All nurses randomly selected nurses working in selected health institutions of Ilu AbaBora zone.

\subsection{Eligibility Criteria}

All nurses working in health institution of Ilu AbaBora zone Were included to the study but, nurses who were absent during the time of the study due to annual, maternal, sick leave were excluded.

\subsection{Sample Size and Sampling Techniques`}

The sample size was calculated using a formula for single population proportion by considering the following assumptions:

$95 \%$ level of confidence interval

$5 \%$ margin of error $(d)$

$50 \%$ as a clinical competence of nurses

$$
\frac{(\mathrm{Z} \alpha / 2) 2 * \mathrm{P} *(1-\mathrm{P})}{\mathrm{d} 2}=\frac{3.84 * 0.25}{0.0025}=\approx 384
$$

Since total number of nurses (273) was less 10,000, it can be corrected using population correction formula ( $\mathrm{n} /(1+$ $[\mathrm{n} / \mathrm{N}])$. Accordingly, the final sample size was 160 .

For selecting study participant systematic random sampling technique was used. First, total sample size of nurse was allocated to each health institution proportional to the number of nurse in each health institution. Then, individual participants in each hospitals was selected every two interval by identifying initial starting participants using a lottery method. The list of nurse in each health institution was obtained from the health facilities administrators.

\subsection{Study Variable}

\subsubsection{Dependent Variables}

Nurses' clinical competence.

\subsubsection{Independent Variables}

Age

Sex

Marital status

Education level

Work experience 
Satisfaction with nursing profession

Average monthly salary

Job position

Information retrieval

Type of health institution

Previous training

Frequency of training

Having guideline/manual

\subsection{Data Collection Tool and Procedure}

To measure nurses' competency, competency inventory for registered nurse (CIRN) was used. CIRN was developed in china and used to evaluate the competence of nurses in various clinical positions in the form of self-evaluation. The tool consisted of 55 items under 7 dimensions including clinical care with 10 items, leadership with 9 items, interpersonal relationships with 8 items), legal-ethical practice with 8 items, professional development with 6 items) teaching-coaching with 6 items and research aptitude-critical thinking with 8 items. The internal reliability Cronbach alpha of the tool was 0.908 for overall scale $0.718-0.903$ for the subscales [17]. The CIRN was scored using the five-point likert scale ranging from 0 to 4 , with incompetency score zero), low competency (score 1), moderate competency (score 2), high or sufficient Competency (score 3) and very high competency (score 4). Based on the mean score of participants mean scores below 2, 2-3 and above 3 were considered as low, moderate and high competence respectively $[17,18]$. The data were collected through selfadministered for over a period of one month by trained data collectors.

\subsection{Data Quality Control}

The quality of data was ensured through training of data collectors, regular supervision, and immediate feedback and reviewing each of completed questionnaires daily by researchers. Pre-test of the questionnaire was conducted on $10 \%$ of sample size on nursing working in two health institutions nearby Ilu AbaBor zone two weeks prior to actual data collection to make sure clarity of the questionnaire. Researchers had also checked each part of the instrument for missed values before data entry and the incomplete data were discarded.

\subsection{Data Analysis}

Data were entered into Epi Data version 4.2.2 and exported to statistical package for the social science (SPSS) version 20.0. Frequencies, means and standard deviations of independent variables and level of depression were analyzed using descriptive statistics. Independent t-test and one way analysis of variance (ANOVA) were used to examine mean difference between groups of independent variables. Independent t-test is parametric test that used to compare mean of two groups and one way analysis of variance (ANOVA) is also parametric that used to compare mean of three or more groups. Therefore independent variables with two groups were analysed by independent $t$ test and variables with three or more groups were analysed by one way ANOVA.

Prior to conduct independent t-test and ANOVA, data were tested for assumption of normality and homogeneity. The assumption normally was tested by creating histogram and values of skewness and kurtosis, and confirmed by Kolmogorov-Smirnov tests at an alpha level of 0.05 . The assumption of homogeneity of variance was examined by Levene's test of equality of variance. The results indicated that there were no significantly different variances among groups, thus assumption of homogeneity of variance for all variables was tenable. The results indicated that there were no non-normally distributed variables. Statistical significance difference was set at $\mathrm{p}<0.05$.

\section{Results}

Socio-Demographic Characteristics of participants

Out of total 160 recruited participants, 156 of them were fully responded the questionnaire making the response rate of $97.5 \%$. Out of fully responded participants $95(60.9 \%)$ of them were male. The mean age of respondents was 29.68 $(\mathrm{SD}=5.33)$. Regarding educational status of participants, more than half $82(52.6 \%)$ of them have only diploma in nursing and majority $115(73.7 \%)$ of them had $1-5$ year of working experience in nursing profession (Table 1).

Table 1. Socio-demographic characteristics of nurses working in selected health institutions of Ilu AbaBor zone, South West Ethiopia, $2019(n=156)$.

\begin{tabular}{lll}
\hline Variables & Frequency & Percent \\
\hline Sex & & \\
Male & 95 & 60,9 \\
Female & 61 & 39.1 \\
Age in year (min=22, max=40, mean=27.72, SD=3.9) & \\
$20-25$ & 43 & 27.6 \\
$26-30$ & 79 & 50.6 \\
$31-35$ & 22 & 14.1 \\
$>35$ & 12 & 7.7 \\
Marital status & & \\
Single & 103 & 66 \\
Married & 53 & 34 \\
Level of education & & \\
Diploma in Nursing & 82 & 52.6 \\
Degree in Nursing & 74 & 47.4 \\
Year of experience (min=1, max $=14$, mean=4.5, SD=2.6) & \\
1 -5 & 115 & 73.7 \\
$6-10$ & 33 & 21.2 \\
$>10$ & 8 & 5.1 \\
Average monthly salary in EB & 72 & 46.2 \\
$3000-5000$ & 75 & 48 \\
$5001-8000$ & 9 & 6 \\
$>8000$ & & \\
\hline & & \\
& &
\end{tabular}

Frequency Distribution of nursing profession related Factors of clinical Competency

As shown on the Table 2 below, most of the respondents $71(45.5 \%)$ were working in health centres and majority of the respondents $136(87.2 \%)$ were serving as staff nurse. Almost half $78(50 \%)$ of respondents were like to retrieve newly published information related to nursing care and most 
of them 116 (74.4) were satisfied with nursing profession. Most of the respondents $129(82.6 \%)$ had at least one type of training in their professional career. Majority 143 (91.7) of them had taken exit exam or COC up on graduation of their current education but $122(78.2 \%)$ of them passed the exam/ COC. More than three fourth 110 (70.5) of respondents had at least one type of guideline/manual but only 91 (58.3) of them were using it.

Table 2. Frequency Distribution of nursing profession related Factors of clinical Competency among nurses working in selected health institutions of Ilu Ababor zone southwest Ethiopia, $2019(n=156)$.

\begin{tabular}{|c|c|c|}
\hline Variables & Frequency & Percentage \\
\hline \multicolumn{3}{|l|}{ Type health facility } \\
\hline Health centre & 71 & 45.5 \\
\hline General hospital & 21 & 13.5 \\
\hline Referral Hospital & 64 & 41 \\
\hline \multicolumn{3}{|l|}{ Position of nurses } \\
\hline Director & 7 & 4.5 \\
\hline Staff nurse & 136 & 87,2 \\
\hline \multicolumn{3}{|c|}{ Do you like to retrieve newly published information related to nursing care? } \\
\hline Yes & 78 & 50 \\
\hline No & 78 & 50 \\
\hline \multicolumn{3}{|c|}{ Are you satisfied with nursing profession? } \\
\hline Yes & 116 & 74.4 \\
\hline No & 39 & 25 \\
\hline \multicolumn{3}{|c|}{ If yes, indicate your level of satisfaction } \\
\hline Average & 66 & 42.3 \\
\hline Low & 12 & 7.7 \\
\hline \multicolumn{3}{|c|}{ Have you ever taken any type of training in your professional career? } \\
\hline Yes & 129 & 82.6 \\
\hline No & 27 & 17.3 \\
\hline \multicolumn{3}{|c|}{ If yes, how many times you have taken the trainings? } \\
\hline $1-3$ & 110 & 71.2 \\
\hline $4-7$ & 9 & 5.8 \\
\hline$>7$ & 10 & 6.4 \\
\hline \multicolumn{3}{|c|}{ Have you taken exit exam or COC up on graduation of your current education? } \\
\hline Yes & 143 & 91.7 \\
\hline No & 13 & 8.3 \\
\hline \multicolumn{3}{|c|}{ If yes, have you passed that Exam/COC? } \\
\hline Yes & 122 & 78.2 \\
\hline No & 22 & 14.1 \\
\hline No & 46 & 29.5 \\
\hline \multicolumn{3}{|c|}{ If yes, are you using it currently? } \\
\hline yes & 91 & 58.3 \\
\hline No & 19 & 12.2 \\
\hline
\end{tabular}

Clinical Competence of Nurses

The overall clinical competence of participants was 2.23 $(\mathrm{SD}=0.6)$ out of a total possible score range from 0 to 4 which indicates moderate level of clinical competency. It was also found that $74(47.4 \%), 50(32.1 \%)$ and 32 (20.5) of participants were in low, moderate and high clinical competency respectively. In compare with other dimension participants were scored better mean 2.34 (0.8) in legal/ethical dimension of clinical competence (Table 3 ).

Table 3. Clinical competency of nurses working in selected health institutions of Ilu Ababor zone southwest Ethiopia, 2019 ( $n=156)$.

\begin{tabular}{|c|c|c|c|c|c|c|c|}
\hline \multirow{2}{*}{ Competency } & \multirow{2}{*}{ Mean (SD) } & \multicolumn{2}{|c|}{ Low competency } & \multicolumn{2}{|c|}{ Moderate competency } & \multicolumn{2}{|c|}{ High competency } \\
\hline & & $\mathbf{N}$ & $\%$ & $\mathbf{N}$ & $\%$ & $\mathbf{N}$ & $\%$ \\
\hline Overall & $2.23(0.6)$ & 74 & 47.4 & 50 & 32.1 & 32 & 20.5 \\
\hline Clinical care & $2.12(0.8)$ & 69 & 44.2 & 56 & 35.9 & 31 & 19.9 \\
\hline Leadership & $2.32(0.82)$ & 63 & 40.4 & 70 & 44.9 & 23 & 14.7 \\
\hline Interpersonal & $2.15(0.52)$ & 59 & 37.8 & 76 & 48.7 & 21 & 13.4 \\
\hline Legal/ethical & $2.34(0.8)$ & 56 & 35.9 & 67 & 42.9 & 33 & 21.2 \\
\hline Teaching coaching & $2.06(0.69)$ & 70 & 44.9 & 67 & 42.9 & 19 & 12.2 \\
\hline Critical thinking & $2.23(0.52)$ & 42 & 26.9 & 99 & 63.5 & 15 & 9.6 \\
\hline
\end{tabular}


Factors associated with clinical competence of nurses

Independent $\mathrm{t}$ - test found that there was no a statistically significant difference between mean scores of groups based on sex; $t(154)=-0.58, \mathrm{p}=0.563, \mathrm{~d}=-.1$, satisfaction with nursing profession; $t(154)=.66, \mathrm{p}=.510, \mathrm{~d}=.13$, taking exit exam or COC up on graduation; $t(154)=0.40, \mathrm{p}=.685$, $\mathrm{d}=.1$ andstatus Passing exit Exam/COC; $t(142)=1.87, \mathrm{p}=.063$, $\mathrm{d}=.4$. However, Statistically significant difference was found between the groups based on marital status; $t(154)=-8.38$, $\mathrm{p}<.001, \mathrm{~d}=-1.5$, Level of education; $t(154)=-6.20, \mathrm{p}<.001$, $\mathrm{d}=-2.0$, newly published information related to nursing care retrieval; $t(154)=3.08, \mathrm{p}<.001, \mathrm{~d}=.3$, any previous training in their professional career; $t(154)=-4.42, \mathrm{p}<.001, \mathrm{~d}=.88$, having guideline/manual; $t(154)=9.44, \mathrm{p}<.001, \mathrm{~d}=2$ and using guideline/manual currently; $t(154)=2.37, \mathrm{p}=0.019 \mathrm{~d}=.5$ (Table 4).

One way analysis of variance (AVOVA) revealed that there was a statistically significant difference in mean scores among groups based age $\mathrm{F}(3,152)=36.32, \mathrm{p}<.001, \eta 2=.4$, work experience $F(2,153)=38.42, p<.001, \eta 2=.3$, level of education $\mathrm{F}(2,153)=22.24, \mathrm{p}=<.001, \eta 2=.2$, current position; $\mathrm{F}(2,153)=51.23, \mathrm{p}<.001, \eta 2=.4$, level of satisfaction $\mathrm{F}(3$, $115)=17.23, \mathrm{p}<.001, \eta 2=.3$, frequency of previous trainings $\mathrm{F}(2,127)=46.56, \mathrm{p}<.001, \eta 2=.4$, average income or monthly salary $F(2,153)=17.97, p<.001, \eta 2=.2$ (Table 5).

Table 4. Independent sample t- test: Factors associated with clinical competence of nurses working in selected health institutions of Ilu Ababor zone southwest Ethiopia, $2019(n=156)$.

\begin{tabular}{|c|c|c|c|c|c|c|c|}
\hline Variables & $\mathbf{N}$ & M (SD) & $\mathbf{t}$ & df & p & D & $95 \%$ CI \\
\hline Sex & & & & & 0.563 & & \\
\hline Male & 95 & $2.20(.60)$ & -0.58 & 154 & & -.1 & $-0.2612-0.1428$ \\
\hline Female & 61 & $2.26(.64)$ & & & & & \\
\hline Marital status & & & & & $<.001$ & & \\
\hline Single & 103 & $1.98(.50)$ & -8.38 & 154 & & -1.5 & $-.9056-.5602$ \\
\hline Married & 53 & $2.71(.54)$ & & & & & \\
\hline Level of education & & & & & $<.001$ & & \\
\hline Diploma in Nursing & 82 & $1.96(.50)$ & -6.20 & 154 & & -2.0 & $-0.5552-0.895$ \\
\hline Degree in Nursing & 74 & $2.52(0.60)$ & & & & & \\
\hline Retrieval ofnewly published information related to nursing care & & & & & $<.001$ & & \\
\hline Yes & 78 & $2.38(.71)$ & 3.08 & 154 & & 0.3 & $.1072-.4904$ \\
\hline No & 78 & $2.08(.46)$ & & & & & \\
\hline \multicolumn{8}{|l|}{ Satisfaction with nursing profession } \\
\hline Yes & 117 & $2.24(.62)$ & .66 & 154 & .510 & 0.13 & $-.1511-.3029$ \\
\hline No & 39 & $2.16(.60)$ & & & & & \\
\hline Previous training & & & & & $<.001$ & & \\
\hline Yes & 129 & $2.13(0.56)$ & -4.42 & 154 & & -.88 & $-.7988-.3056$ \\
\hline No & 27 & $2.68(.69)$ & & & & & \\
\hline taking exit exam or COC up on graduation & & & & & 0.685 & & \\
\hline Yes & 143 & $2.23(.61)$ & 0.40 & 154 & & 0.1 & $-.2834-.4304$ \\
\hline No & 13 & $2.16(.67)$ & & & & & \\
\hline Passed exit Exam/COC & & & & & .063 & & \\
\hline Yes & 122 & $2.27(.62)$ & 1.87 & 142 & & 0.4 & $-.0149-.5468$ \\
\hline No & 22 & $2.00(.50)$ & & & & & \\
\hline Having guideline/manual that help in providinghealth service & & & & & $<.001$ & & \\
\hline Yes & 110 & $2.47(.58)$ & 9.44 & 154 & & 2 & $0.6514-0.9959$ \\
\hline No & 46 & $1.65(.07)$ & & & & & \\
\hline Using guideline/manual currently & & & & & 0.019 & & \\
\hline yes & 91 & $2.53(.59)$ & 2.37 & 108 & & 0.5 & $.0570-.6329$ \\
\hline No & 19 & $2.18(.48)$ & & & & & \\
\hline
\end{tabular}

Table 5. Analysis of variance (ANOVA): Factors associated with clinical competence of nurses working in selected health institutions of Ilu Ababor zone southwest Ethiopia, $2019(n=156)$.

\begin{tabular}{|c|c|c|c|c|c|c|}
\hline Variables & $\mathbf{N}$ & M (SD) & Df & $\mathbf{F}$ & $\mathbf{P}$ & $\eta$ \\
\hline \multicolumn{7}{|l|}{ Age } \\
\hline $20-25$ & 42 & $2.07(.75)$ & 3,152 & 36.328 & $<0.001$ & 0.4 \\
\hline $26-30$ & 79 & $2.02(.30)$ & & & & \\
\hline $31-35$ & 22 & $2.60(.46)$ & & & & \\
\hline$>35$ & 13 & $3,38(.09)$ & & & & \\
\hline \multicolumn{7}{|l|}{ Year of experience } \\
\hline $1-5$ & 115 & $2.03(.43)$ & 2,153 & 38.426 & $<0.001$ & 0.3 \\
\hline$>10$ & 8 & $3.32(.39)$ & & & & \\
\hline \multicolumn{7}{|l|}{ Type health facility } \\
\hline Health center & 71 & $1.94(.38)$ & & & & \\
\hline General hospital & 21 & $2.78(.71)$ & 2,153 & 22.24 & $<0.001$ & 0.2 \\
\hline Referral Hospital & 64 & $2.36(.64)$ & & & & \\
\hline
\end{tabular}




\begin{tabular}{|c|c|c|c|c|c|c|}
\hline Variables & $\mathbf{N}$ & M (SD) & Df & $\mathbf{F}$ & $\mathbf{P}$ & $\eta$ \\
\hline \multicolumn{7}{|c|}{ Position in thehealth facility } \\
\hline Director & 7 & $2.92(.65)$ & 2,153 & 51.23 & $<0.001$ & 0.4 \\
\hline Staff nurse & 136 & $2.08(.49)$ & & & & \\
\hline Head nurse & 13 & $3.40(.08)$ & & & & \\
\hline \multicolumn{7}{|c|}{ level of satisfaction } \\
\hline Very high & 29 & $2.75(.74)$ & 3,115 & 17.23 & $<0.001$ & 0.3 \\
\hline Rather high & 12 & $2.76(.80)$ & & & & \\
\hline Low & 12 & $2.16(.67)$ & & & & \\
\hline \multicolumn{7}{|c|}{ Frequency of trainings } \\
\hline $1-3$ & 110 & $2.03(.44)$ & 2,127 & 46.56 & $<0.001$ & 0.4 \\
\hline $4-7$ & 9 & $2.02(.56)$ & & & & \\
\hline$>7$ & 10 & $3.41(.07)$ & & & & \\
\hline \multicolumn{7}{|c|}{ Average monthly salary in ETB } \\
\hline $3000-5000$ & 72 & $1.97(.40)$ & 2,153 & 17.97 & $<0.001$ & 0.2 \\
\hline$>8000$ & 9 & $2.95(.76)$ & & & & \\
\hline
\end{tabular}

\section{Discussion}

In the present study $74(47.4 \%), 50(32.1 \%)$ and 32 $(20.5 \%)$ of participants were in low, moderate and high clinical competence level respectively. In contrary to present finding, several previous studies have reported better finding that $58.3 \%$ of participants were in moderate level and $34.3 \%$ participants were in high level in Iran [18], $80 \%$ of participants were highly competent in Iran [19] and $67.5 \%$ of participants were in high level in Finland [20]. This discrepancy may be due difference in nursing education facilities, accessibility and availability of teaching centre, health care system and technology advancement.

The current study also found that the mean score of participants was $2.23 \pm 0.6$ on five point likert scale (0-4). In addition participants had higher competence score on Legal/ethical dimension and lower competence score on teaching coaching dimension. Participants' scores in current study was notably less than score in the previous study which reported $2.70 \pm 0.46$ from 4 total score. The mean score of participants on professional development, interpersonal communication and ethics and professional morality were higher than the mean score participants of current study [21]. This difference from previous study may be attributable to higher levels of education and longer periods of work experience in prior study, which may have increased nurses' confidence in their clinical competence.

The present study found that a significant difference in mean score of clinical competence of nurses based on age groups in which older nurses were scored higher than younger nurses. Study in Iran [19, 22] and Finland [23] reported similar finding that clinical competence was significantly associated with age. The reason for this may be older nurses had more opportunities of exposure to different nursing care than younger nurses. Participants with higher educational level scored significantly higher than those with lower educational level. This finding is consistent with other published studies in Finland [16, 20, 23] This could be due to nursing education in BSc nursing curriculum may benefited degree nurse to have higher clinical competence.

This study also revealed that a significant association between years of nursing work experience and clinical competence of nurses. Studies in Finland [16] and Iran [18, $22,24]$ reported similar finding that year of experience was significantly associated with the mean scores of nurses. The possible explanation for this may be their exposure to different patients for long period of time might positively influence their clinical competence level. The previous study found that clinical competence of nurses was associated with position of nurse [22]. The present study also support this finding that statistically significant difference in clinical competence mean scores between groups of participants by current role.

Statistically significant difference was found between single participants and married participants in the present study. This finding is congruent with finding of study done in Iran [18] in which competency of married individuals was higher than that of the unmarried. The present finding did not found significant difference of mean scores of clinical competence based satisfaction of nurses to their work. Incongruent to this, prior study showed that nurses who had higher satisfaction to their work had the highest mean scores of clinical competence when compared with nurse who had less satisfaction [16]. Possible explanation for this may be due to difference in measurement scale or work environment. In line with study conducted in Iran [25], the present study also did not found statistically significant difference of mean scores of clinical competence based sex of nurses.

Participants who had any type of training in their professional career, who had guideline/manual that help them in providing health service and who have been using guideline/manual currently were more clinically competent than their counterparts. This could due to their updated knowledge positively influence their clinical competence. However, there are no previous studies that examined association between clinical competence and these factors. Thus, further research investigating the relationship between these variables is needed to confirm the present result. 


\section{Limitations}

There are some potential limitations of this study that should be kept in mind when interpreting the findings. First, the participants were from only Ilu AbaBor zone. This limitation did not allow for generalizability of the findings to the entire nurses in the country. Second, the cross-sectional nature of the study design limits the ability to draw conclusions about definitive cause and effect relationship. Lastly since this study was based on participants' reports of their competence, there may be recall bias.

\section{Conclusion}

In the current rapidly changing healthcare environment, the need for clinical competence among nurses is continually increasing. However, clinical competence of nurses in the current study was inadequate in which the overall score of participants was almost half of total score (4). Participants had higher competence score on Legal/ethical dimension and lower competence score on teaching coaching dimension. Age, marital status, level of education, work experience, type of health facility, average income, and current position, retrieval of newly published information, previous training, and frequency of trainings, having guideline/manual and using guideline/manual currently were the identified factors association with clinical competence of nurses.

Based on the findings of this study it is recommended that health policy makers should set strategies to assess the level of clinical competency of nurses on a periodic basis in order to assure quality nursing service provided in different nursing positions. Health institution managers should also work to tackle the factors that have contributed to lower the clinical competency of nurses.

\section{Abbreviation}

ANOVA, Analysis of Variance; CI, Confidence Interval; CIRN, Competency Inventory for Registered Nurses; SPSS, Statistical Package For Social Science.

\section{Ethical Approval}

Ethical approval was taken from Mettu University, College of health sciences, and department of nursing. Permission was obtained from each hospital after supportive letter was given. Informed consent was taken from participants. Confidentiality and privacy was also ensured for participants.

\section{Data Sharing Statement}

The data used during the current study are available from the corresponding author on reasonable request.

\section{Author Contributions}

All authors made ample contributions this study. For the submission of this study all authors also approved the final version.

\section{Funding}

This study was employed in collaboration with Mettu University.

\section{Disclosure}

All authors declare nonexistence of competing interests.

\section{Acknowledgements}

Our sincere appreciation goes to Mettu University, for giving us the opportunity to conduct this study. We would also like to extend our deepest thanks to the data collectors and participants for being involved in the study.

\section{References}

[1] Levett-Jones T, Gersbach J, Arthur C, Roche J. Implementing a clinical competency assessment model that promotes critical reflection and ensures nursing graduates' readiness for professional practice. Nurse Education in Practice. 2011; 11 (1): 64-9.

[2] Borhani F, Alhani F, Mohammadi E, Abbaszadeh A. Professional Ethical Competence in nursing: the role of nursing instructors. Journal of medical ethics and history of medicine. 2010; 3 .

[3] Faraji A, Karimi M, Azizi SM, Janatolmakan M, Khatony A. Evaluation of clinical competence and its related factors among ICU nurses in Kermanshah-Iran: A cross-sectional study. International journal of nursing sciences. 2019; 6 (4): 421-5.

[4] Roberts K, Lockhart R, Sportsman S. A competency transcript to assess and personalize new graduate competency. JONA: The Journal of Nursing Administration. 2009; 39 (1): 19-25.

[5] Moatary M, Akaberian S, Mirzaie K. Determining nurses' clinical competence in hospitals of Bushehr University of Medical Sciences by self assessment method. ISMJ. 2008; 11 (1): 69-75.

[6] Kemppainen V, Tossavainen K, Turunen H. Nurses' roles in health promotion practice: an integrative review. Health Promotion International. 2013; 28 (4): 490-501.

[7] Manoochehri H, Imani E, Atashzadeh-Shoorideh F, AlaviMajd A. Competence of novice nurses: role of clinical work during studying. Journal of medicine and life. 2015; 8 (Spec Iss 4): 32 .

[8] Kuokkanen L, Leino-Kilpi H, Numminen O, Isoaho $\mathrm{H}$, Flinkman M, Meretoja R. Newly graduated nurses' empowerment regarding professional competence and other work-related factors. BMC nursing. 2016; 15 (1): 22.

[9] Numminen O, Leino-Kilpi H, Isoaho H, Meretoja R. Newly graduated nurses' competence and individual and organizational factors: A multivariate analysis. Journal of Nursing Scholarship. 2015; 47 (5): 446-57. 
[10] Park MS, Jeoung Y, Lee HK, Sok SR. Relationships among communication competence, self-efficacy, and job satisfaction in Korean nurses working in the emergency medical center setting. Journal of nursing research. 2015; 23 (2): 101-8.

[11] Kim K, Han Y, Kwak Y, Kim J-s. Professional quality of life and clinical competencies among Korean nurses. Asian nursing research. 2015; 9 (3): 200-6.

[12] Mirlashari J, Qommi R, Nariman S, Bahrani N, Begjani J. Clinical competence and its related factors of nurses in neonatal intensive care units. Journal of caring sciences. 2016; 5 (4): 317.

[13] Jiang L, He HG, Zhou WG, Shi SH, Yin TT, Kong Y. Knowledge, attitudes and competence in nursing practice of typhoon disaster relief work among $\mathrm{C}$ hinese nurses: a questionnaire survey. International journal of nursing practice. 2015; 21 (1): 60-9.

[14] Susan Sportsman R, editor Competency education and validation in the United States: what should nurses know? Nursing forum; 2010: Blackwell Publishing Ltd.

[15] Bifftu BB, Dachew BA, Tadesse Tiruneh B, Mekonnen Kelkay M, Bayu NH. Perceived clinical competence among undergraduate nursing students in the university of Gondar and Bahir Dar university, Northwest Ethiopia: A crosssectional institution based study. Advances in Nursing. 2016; 2016.

[16] Istomina N, Suominen T, Razbadauskas A, Martinkènas A, Meretoja R, Leino-Kilpi H. Competence of nurses and factors associated with it. Medicina. 2011; 47 (4): 33.

[17] Liu M, Yin L, Ma E, Lo S, Zeng L. Competency inventory for registered nurses in Macao: instrument validation. Journal of advanced nursing. 2009; 65 (4): 893-900.

[18] Karami A, Farokhzadian J, Foroughameri G. Nurses' professional competency and organizational commitment: is it important for human resource management? PloS one. 2017; 12 (11): $\mathrm{e} 0187863$.

[19] Keykha R, Mazlum S, Varasteh S, Arbabisarjou A. Clinical competency and its related factors in nurses. International Journal of Pharmacy and Technology. 2016; 8 (3): Lakanmaa RL.

[20] Lakanmaa R-L, Suominen T, Ritmala-Castrén M, Vahlberg T, Leino-Kilpi H. Basic competence of intensive care unit nurses: cross-sectional survey study. BioMed research international. $2015 ; 2015$.

[21] Ramezanzade Tabriz E, Orooji A, Bikverdi M. Investigation clinical competence and its relationship with professional Ethics and spiritual health in nurses. Health, Spirituality and Medical Ethics. 2017; 4 (1): 2-9.

[22] Khodadadei N, Rezaei B, Salehi S. Investigating the Relationship of Organizational Commitment and Clinical Competence (Case study: Nurses Working in Montazeri Hospital, City of Najafabad, Iran, 2015). Health Sciences. 2016; 5 (5): 308-16.

[23] Salonen AH, Kaunonen M, Meretoja R, TARKKA MT. Competence profiles of recently registered nurses working in intensive and emergency settings. Journal of Nursing Management. 2007; 15 (8): 792-800.

[24] Goliroshan S, Babanataj R, Aziznejadroshan P. Investigating the Self-assessment of Clinical Competency of Nurses Working in Babol University of Medical Sciences Hospitals. World Family Medicine Journal: Incorporating the Middle East Journal of Family Medicine. 2018; 99 (5897): 1-6.

[25] Soheilipour K, Farajzadeh Z. Evaluating the clinical competence of junior nursing staff based on selfassessmentinValiasr Hospital of Birjand in 2015-16. Modern Care Journal. 2016; 13 (4): e10089. 